\title{
Effect of spring stiffness and coefficient of friction on the stresses distribution and die angle in extrusion process
}

\author{
Hani Aziz Ameen \\ Pumps Engineering Department, Technical College /Al-Musaib-Iraq \\ E-mail: haniazizameen@yahoo.com \\ ABSTRACT
}

\begin{abstract}
The main objective of this study is to find the best angle for the extrusion die by linking the die with springs having different stiffness and the die having different coefficient of friction. The Model of this study Consider the visco-plastic case for the material and the coefficient of friction between the die and the metal flow where the coefficient of friction value are $(0.005,0.008,0.015)$. A numerical solution considered the element (visco106) for the metal, the element (beam3) for the die and the element (combin14) for the spring stiffness. The spring stiffness' vary $(100 \mathrm{~N} / \mathrm{mm}, 1000 \mathrm{~N} / \mathrm{mm}$ and $10000 \mathrm{~N} / \mathrm{mm}$ ). The model considered in this work is the axi-symmtric model where this model considered the non-linear method of three elements to solve this problem and the effect of the friction in the solution which explain it by friction surface to surface by using the element (contac171 and targ169) and Newton-Raphson method using ANSYS code was adopted to solve this model. The thesis focuses on two parts, theoretical part and experimental part .In the theoretical part the extrusion process is investigated by using ANSYS software to demonstrate the stress distributions in the billet with several cases of stiffness and coefficient of friction, this program depends on the finite element method in the analysis. On the other hand the apparatus of the extrusion process is made to study this process and to find the best angle for the extrusion die. The material of the billet that was used in the extrusion process was wax. The selection of Paraffin wax is not randomly, this because it has the behaviors of the metal. The experimental part is done depending on the theoretical part and prepared the samples according to the standard methods with choosing slow and fixed velocity of extrusion; the assembly of extrusion is designed by using Acrylic material it is also used in order that the process can be photo and bearing the high pressure of extrusion process. In this study, casting the Paraffin wax in especial die, and manufacture the extrusion instrument containing upper and lower plate and the metal spring fixing at the beginning of the die and it has the stiffness $(100 \mathrm{~N} / \mathrm{mm}, 1000 \mathrm{~N} / \mathrm{mm}, 10000 \mathrm{~N} / \mathrm{mm})$. The results show good agreement between the theoretical and experimental results for distributing of the strain and stress in metal at different point in the die under different boundary conditions. The reduction of area considered to be variable in two cases with lubricate (16.6, 22.2 and 27.7) and with out lubricate (22.2, 24.4 and 26.6) and it was found that the force-displacement curve at the case of variable coefficient of friction effect on the die angle, where the best die angle is $8.7^{\circ}$ when the stiffness of the spring is $K=10000 \mathrm{~N} / \mathrm{mm}$ and coefficient of friction is $\mu$ $=0.005$.
\end{abstract}

Keywords: Extrusion, Die Design, Finite Element Method, ANSYS Software

\section{INTRODUCTION}

Metal forming includes a large group of manufacturing processes in which plastic deformation is used to change the shape of metal work pieces. Deformation results from the use of a tool, usually a die in metal forming, which applies stresses that exceed the yield strength of the metal. The metal therefore deforms to take a shape determined by the geometry of the die (Altan and Gegel, 1983). Extrusion is a forming process in which metal is shaped by being forced through a die. Slip line field technique and hodographs are used in the analysis of plane strain extrusion process (Johnson and Mellor, 1972). A more simple technique is suggested which considers the conditions of deformation caused the increment of strain throughout the deformation cycle. This solution is called "upper bound technique" (Frisch and Pietri, 1977). Visco-plasticity method (Banabic,2000) has been used to analyze the metal flow during the deformation cycle. With the development of the computer simulation of the metal forming processes using methods such as the finite element method, empirical design procedures using computer simulation were being developed. A systematic study of some of die design problem was done by Kobayashi, 1989. The elastic-plastic finite element methods have been used to solve a variety of problem in elasto plasticity such as extrusion (Nayak and Zienkiewics, 1972). A finite element method for rigid-plastic analysis of metal forming-formulation for finite deformation was formulated by Osakada et 
al, 1982. A method based on equilibrium of nodal forces was proposed by assuming the deforming metal to be slightly compressible rigid-plastic material. As for extrusion of the metal, a formulation for finite deformation is derived on the basis of the equilibrium of nodal force at the end of incremental deformation. The effect of work hardening and shape change of element during the incremental deformation is incorporated. This formulation is more accurate than that of simple extrusion of infinitesimal deformation when dealing with nonsteady problems, and is particularly effective for the process in which the mode of deformation is sensitively changed by the distribution of the flow stress and variation in shape. Balaji et al,1991 developed a generalized methodology complied with a rigid visco-plastic model ,which simultaneously predicts the deformation field, optimal die design and plastic boundaries of an axisymmetric third order polynomial streamlined dies. The variation power is minimized in the trial plastic domain using FEM, to overcome the shortcoming of the upper bound technique, in satisfying stress equilibrium every where in deformation zone with velocity field, and to overcome the drawback of approximate solution of the slip-line and tends are in reasonable agreement with the experimental observations, and the proposed methodology can be extended to analyze other method working operations. Onuh et al, 2003 carried out an investigation on the effects of the die reduction in area, die angle, loading rate on the quality of the extrusion products, extrusion pressure and flow pattern of cold extruded aluminum and lead alloys shapes of inner circular sections with four symmetrical projections. Results show that the non-dimensionalised values of specific coring pressures and maximum extrusion pressure depend primarily on the die angle, loading state and total reduction in the area of cross-section of the complex shaped section. Bhavin et al,2005 described a new methodology of using design of experiments as a precursor to identify the importance of some variables and, thus reduce the data set needed for training a neural network. The modified method was coded in C-language, and the result were compared with the FEM solution of the same die geometry. The method is significantly faster than the FEM. According to the previous works, it is suggested for using the springs linked to the die to find the best die angle by manufacturing a complete system and to simulate the process by using ANSYS package version 10.

Nonlinear Finite Element Formulation: The formulation can be expressed mainly by three type of nonlinearities: Geometric nonlinearly, Material nonlinearly and Contact nonlinearly. The entire process of performing a finite element analysis of a metal forming operation is shown in Fig. (1).

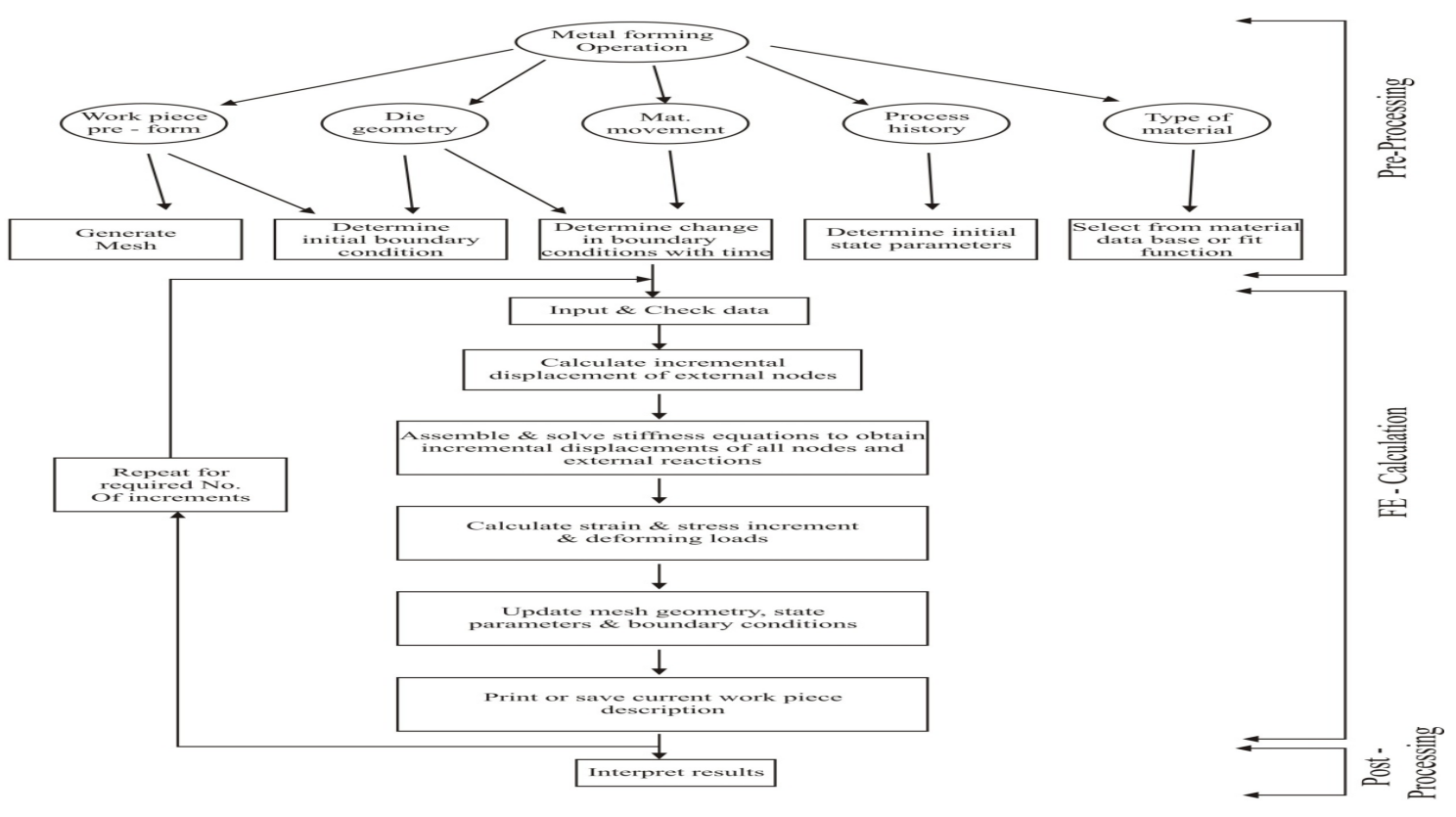

Fig 1: Schematic Representation of the FE Analysis (Osaka et al,1982) 
For a variety of reasons ANSYS10 is often very efficient in solving the metal forming problems. There are six types of elements used in the analysis of extrusion process (in present work)(ANSYS manual,2006) :

Visco 106 -2D Large Strain Solid : Visco 106 used for 2D modeling of solid structure; it can be used either as plane strain or as an axisymmetric element, and is defined by four nodes having up to two degrees of freedom at each node. Translation in the nodal $X \& Y$ directions, the element designed to solve both rate-independent and rate-dependent large strain plasticity problems.

Target 169: It is used to represent various 2D rigid "target" surfaces for the associated contact element (contact 171,contact 172) the contact elements themselves overlay the visco element describing the boundary of a deformable body and are potentially in contact with the rigid target surfaces, defined by target 169 . These target surfaces are discredited by set of target segment elements and paired, is associated contact surface via a shared real constant set.
Contact 171: It used to represent contact and sliding between 2D target surface (169) and deformable surface, defined by this element. This element has two degrees of freedom at each node, translation in node X\&Y directions. Contact occurs when the element surface penetrates one of the target segment elements (target 169) on a specified target surface.Coulomb and shear stress friction are allowed

Combin14: It has longitudinal capability in one or two-dimensional, the longitudinal spring-damper option is a uniaxial tension-compression element with up to two degrees of freedom: translation in $\mathrm{X}$ \& $Y$.

Beam3: It is a uniaxial element with tension, compression and bending capabilities, such element has three degrees of freedom at each node: translation in nodal $X \& Y$ directions and rotation about the node $Z$ - axis.

Fig.(2) shows the element types used in the analysis of extrusion process through tilting die:

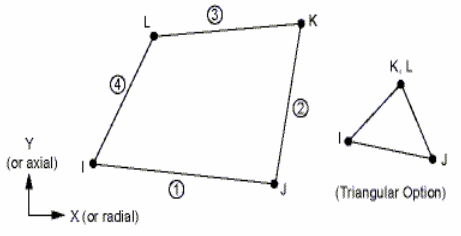

visco106

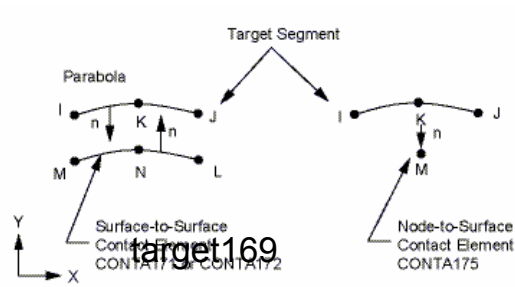

Associated Target Surface

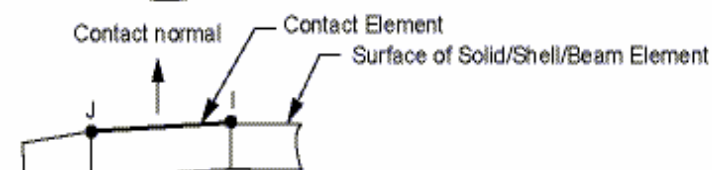

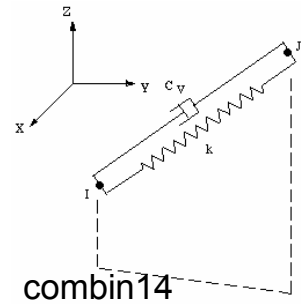

combin 14



Fig 2: ANSYS Elements Types

Modeling Generation: In order to build the model and depending on the nature of the structure, first the suitable elements are chosen, modern finite element computer package ANSYS allows various combinations of different element type and hence make finite elements modeling highly versatile, therefore the element visco106 -2D large strain is selected to indicate the billet, beam3 to designate the dies and combin 14 for the springs. We should take under our consideration that in additional to influences size of element on the convergence of the solution, the number of elements to be chosen for idealization is related to the accuracy- desired size of elements. In this study, simplifying the 
physical configuration body by considers the model is axisymmetric due to symmetric the external condition. The contact status is non-linear, therefore, Rigid-to- flexible contact option is selected. In this case, of contact one or more of the contacting surfaces are treated as rigid which it has much higher stiffness relative to the deformable body it contacts, The rigid surface referred to as the "target" surface and modeled with element named "target 169". The surface of the deformable body referred to as the "contact" surface and modeled with elements named "contact 171". In addition, a contact model surface- to - surface contact is assumed. After defining the element type, it needs to select the contact real constant set and material prosperities. ANSYS uses the material properties of the underlying element to calculate appropriated contact stiffness. In addition, all linear material properties can be input as a function of temperature and input with (MP) family of commands. The final step for building this model are applying loads and obtaining the solutions. The word loads includes boundary conditions and externally or internally forces functions. In addition to the billet and die shape, there are four common process parameters that are identical in all the simulations in order to perform a valid comparison; billet material properties, ram speed, initial temperature, and friction. The excellent formability of paraffin wax makes them strong candidates for extrusion processes.

The finite element model as shown in Fig.(3).

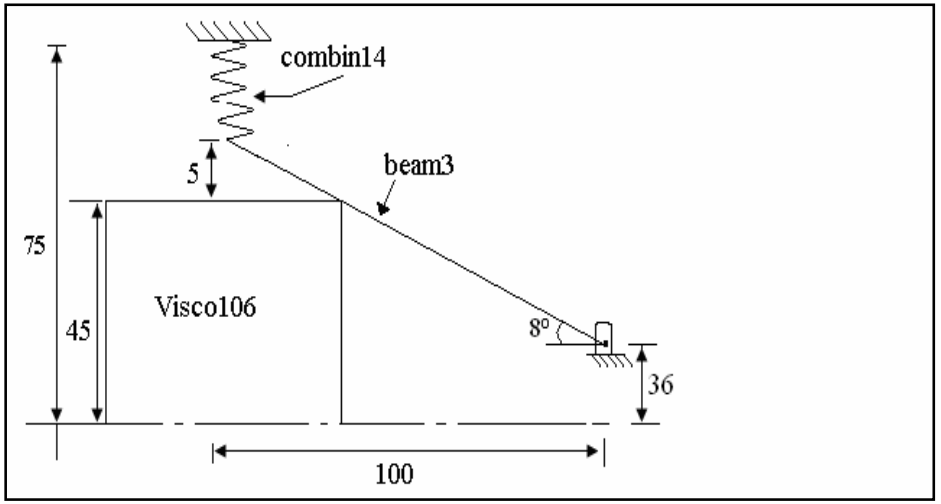

Fig 3: The Geometry of the Process

The material for the billet is paraffin wax with mechanical properties shown in the table (1) (Shabaik and Thumson, 1986).

Table 1: Mechanical Properties of the Paraffin Wax

\begin{tabular}{|l|l|}
\hline Value & Property \\
\hline $7.2 \mathrm{MN} / \mathrm{mm}^{2}$ & Young modulus (E) \\
\hline 0.4 & Passions ratio ( ) for wax \\
\hline $0.15 \mathrm{MN} / \mathrm{mm}^{2}$ & Yield stress ( y ) \\
\hline 0.02 & Coefficient of friction ( ) \\
\hline $0.15 \mathrm{MN} / \mathrm{mm}^{2}$ & Ultimate tensile stress \\
\hline $860 \mathrm{~kg} / \mathrm{m}$ & Density \\
\hline
\end{tabular}

The billet was modeled with (visco 106) element, the die was modeled with (beam 3) linked with spring modeled with (combin 14) the boundary condition of the process where the die is hinged in one end and linked with spring in the other end, the stiffness of the spring varies from $K=100 \mathrm{~N} / \mathrm{mm}$, $\mathrm{K}=1000 \mathrm{~N} / \mathrm{mm}$ and $\mathrm{K}=10000 \mathrm{~N} / \mathrm{mm}$.

The following figure shows the mesh of the modeling explained in Fig.(4)

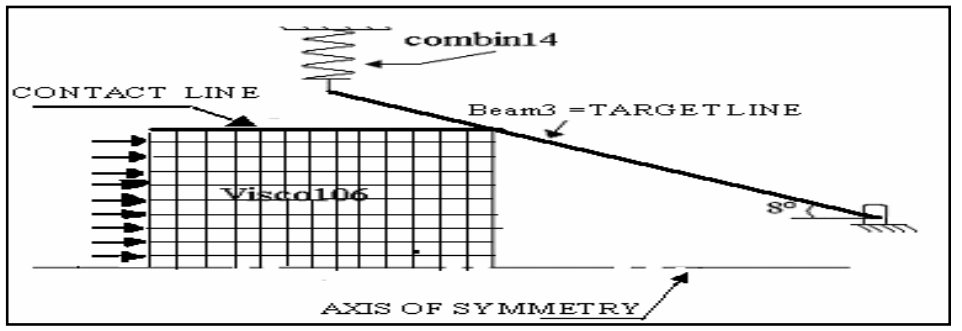

Fig 4: The Mesh Geometry 
Experimental Work: The experimental part is investigated to accomplish the study of hot extrusion with tilting dies, since the exact solutions are so difficult to obtain. The experimental analysis is considered, since it gives real solutions where the engineer problems based on, as well as it is receiving much attention in engineering and industry. Also it gives the operational definition for a particular problem.

Test Apparatus: The direct extrusion system is manufactured, as in Fig.(5)

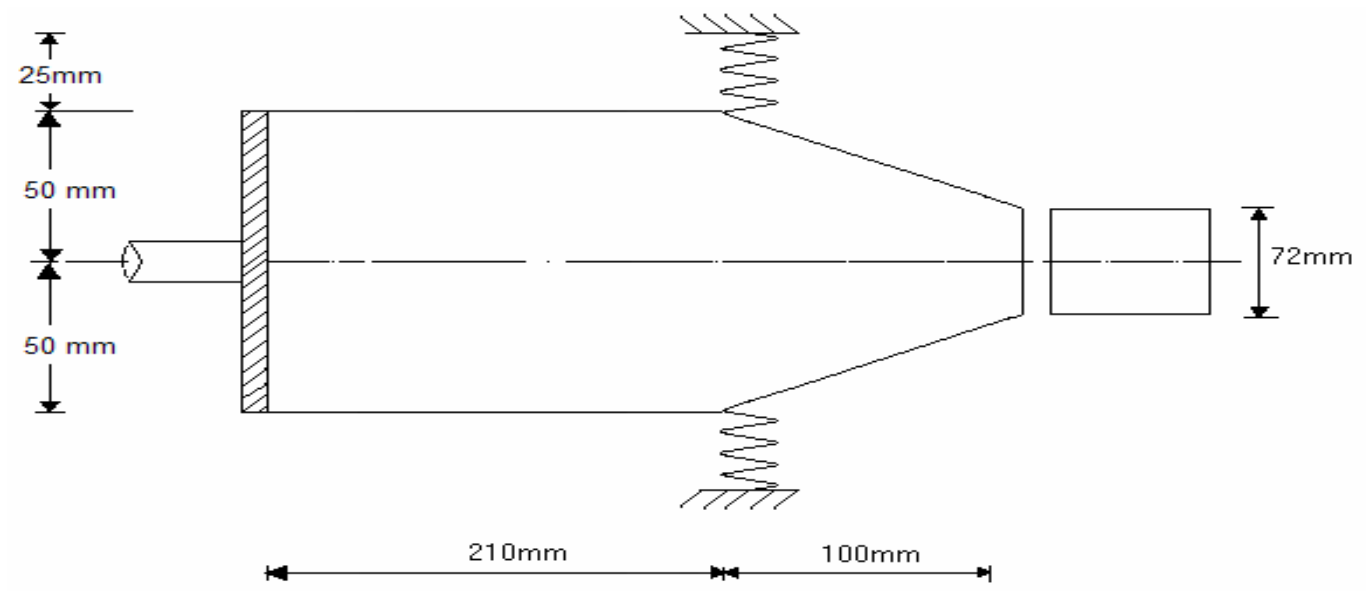

Fig 5: Schematic diagram of the extrusion process

Dies and Container: The die has the dimension $12 \mathrm{~mm}$ ) with a rectangular cross-section and taper (length $=100 \mathrm{~mm}$, width $=35 \mathrm{~mm}$, thickness $=$ as shown

in

Fig.(6).

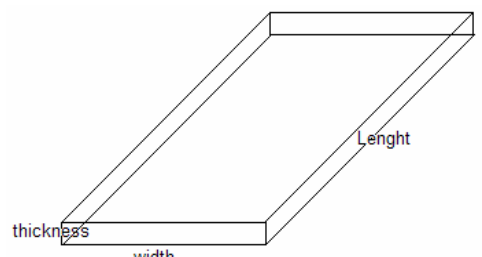

Fidg 6: Dimension of the plate of the die

The dimensions of container are $(210,200,12) \mathrm{mm}$ the die is linked with spring of stiffness' $(100,1000$, 10000) $\mathrm{N} / \mathrm{mm}$. The acrylic is used to manufacture the die, using CNC machine (milling machine) with smoothing the internal surfaces to facilitate the sliding of billet. The plates in the front side and backside are made from acrylic sheets with dimensions $(200,233,11) \mathrm{mm}$ in order to avoid the buckling during extrusion process and to see the movement of billet through the extrusion process. The manufacturing of die is made to ensure the existence of the billet after finishing the extrusion process, by assembling the sides of the acrylic die with the transparency faces using four bolts and nut M6. Fig.(7) explains the part of the die used in the test.

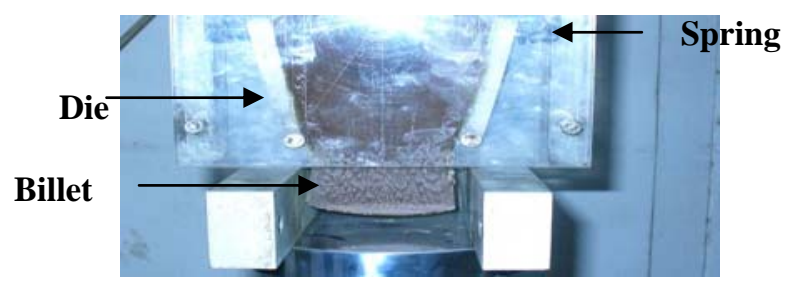

Fig 7: Shows the using die in the test 
Upper Plate: The upper plat is made of carbon steel (ST-37) with diameter $152 \mathrm{~mm}$ and fixed on it the following:

Sheet: welded on the upper surface of the bar, with equal space from the side, is used to apply the loads during the tests.

Ram: The ram is made of acrylic with dimensions $(209,88,35) \mathrm{mm}$ and is fixed on the lower surface of the bar with equal spaces on the ends of the bar. The clearance is taken into consideration with $1 \mathrm{~mm}$ from all sides of the ram to avoid friction between the ram and internal surface of the die and the edges of the ram is filleted, to avoid the stress concentration.
Directors: The directors are made of acrylic and the directors used to guide the movement of the upper plate in order to achieve the perpendicular between the ram and die and as a result to achieve the perpendicular to die parts. The dimensions of the director are $(210,35,35) \mathrm{mm}$ and it's geared with upper plate. The directors are fixed with acrylic faces with 2 bolts for each one.

Lower Plate: The lower plate is made of carbon steel (ST-37), it represents as a base for fixing the die by two bolts and nut M8. Fig.(8) shows the two plates (upper and lower) of the extrusion apparatus.

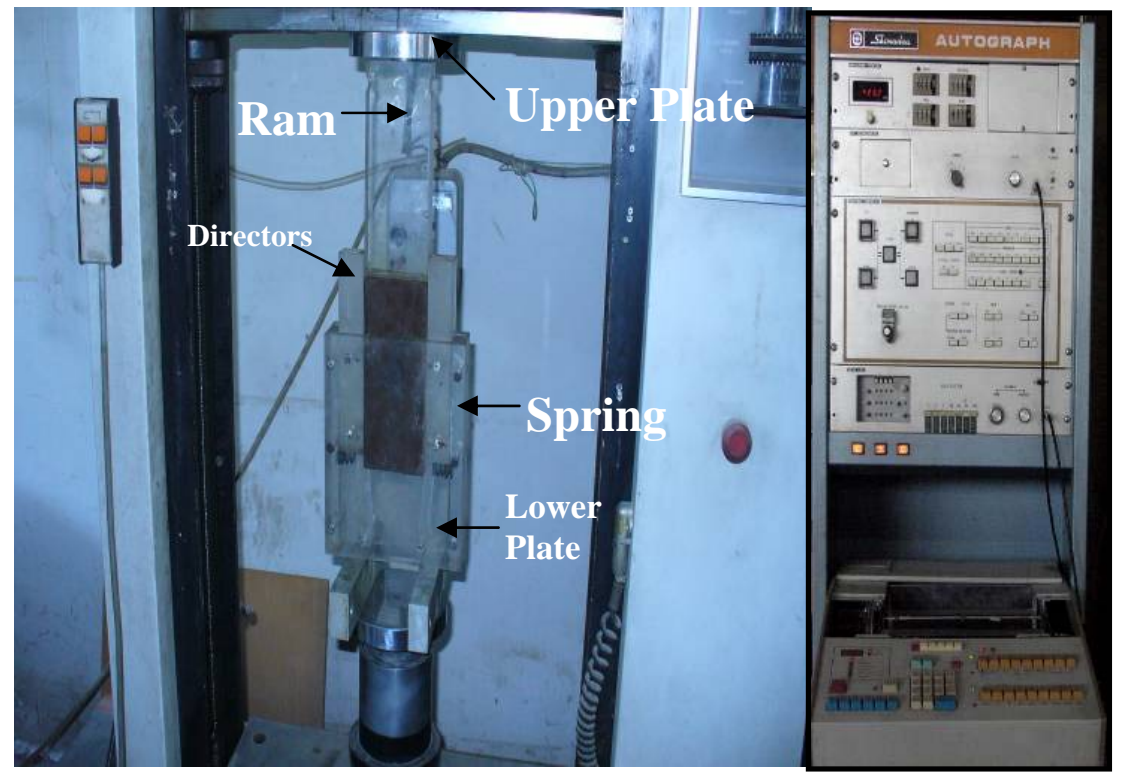

Fig 8: Overall picture of experimental set- up

Springs: Three types of helical springs are used (as in Fig.(9)) in the experiment and it is made of low carbon steel. The aim of using spring is that to fix the die and to get the required angle for die also in order to give a more practical meaning to tilting dies extrusion. The springs had the following dimension as revealed table (2):

Material Model: The paraffin wax is used and it is not randomly selected because it has properties behaves as a metal that yields to the stress-strain curve. The properties of the paraffin wax can be summarized as follows :
1- The re-crystallization temperature ( $\mathrm{Tr})$ is low and is less than the room temperature.

2- The forming process is identical to the hot steel forming and behavior of wax (stress-strain) is the same as the behavior of hot steel.

3-The paraffin does not have any strain hardening.

4- Easy to make the specimens

5- Low cost.

The specifications of the paraffin wax according to the document from Al-Dora refinery are shown in table (3): 
Am. J. Sci. Ind. Res., 2010, 1(2): 164-179

Table 2: Dimensions of Springs

\begin{tabular}{|c|c|c|c|c|c|}
\hline Spring no. & $\mathrm{K}(\mathrm{N} / \mathrm{mm})$ & $D(\mathrm{~mm})$ & $\mathbf{d}_{\text {coil }}(\mathrm{mm})$ & $h_{0}(m m)$ & $h_{f}(\mathrm{~mm})$ \\
\hline 1 & 10000 & 18 & 3 & 30 & 17 \\
\hline 2 & 1000 & 17.5 & 2.3 & 30 & 18 \\
\hline 3 & 100 & 17.8 & 2.2 & 30 & 19 \\
\hline
\end{tabular}

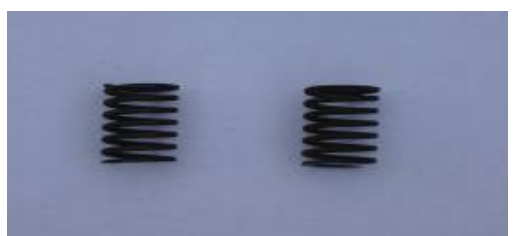

(a)

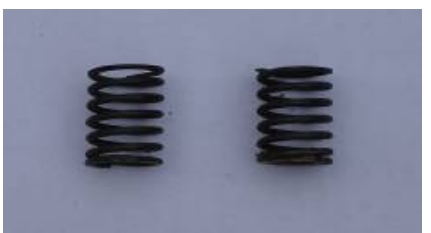

(b)

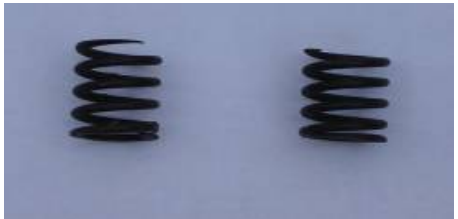

(c)

Fig 9: The type of spring used a- spring no.1 b-spring no.2 c-spring no.3

Table 3: The Mechanical Properties of Paraffin Wax

\begin{tabular}{|l|l|l|l|l|l|l|}
\hline Material & Density & $\begin{array}{l}\text { Melting point } \\
(\mathrm{Tm})\end{array}$ & Oil constant & $\begin{array}{l}\text { Yield } \\
\text { stress }\end{array}$ & $\begin{array}{l}\text { Modulus } \\
\text { Elasticity }\end{array}$ & $\begin{array}{l}\text { Possion } \\
\text { ratio }\end{array}$ \\
\hline Wax & $860 \mathrm{Kg} / \mathrm{m}^{3}$ & $63-68 \mathrm{C}^{\circ}$ & $1 \%$ & $150 \mathrm{Kpa}$ & $7.2 \mathrm{Mpa}$ & 0.4 \\
\hline
\end{tabular}

Fig.(10) shows the material used in the extrusion process, it was paraffin wax.

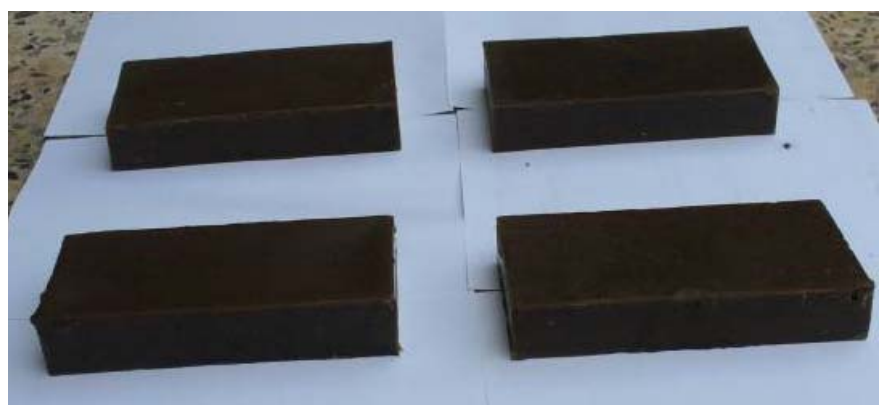

\section{Procedure:}

1- Make the die from acrylic material and then refinery the dimensions of the die by using $\mathrm{CNC}$ Machine to get a close tolerance in addition to smooth surfaces and then tested the springs stiffness by compression test then linked with the spring $(100,1000$ and 10000) N/mm.

2- Fixing the die on the lower plate of the apparatus using 2 bolts and nutM8.

3- The coefficients of friction of the lubricating used in the process are specified as $(0.005,0.008$ and 0.015 ); these coefficients of friction are selected according to standard of the lubricants used in the extrusion process. Other types of lubricants give different values.

4- After placing the sample in the extrusion apparatus and for making the extrusion process, the speed functional was $5 \mathrm{~mm} / \mathrm{min}$ and the load is gradually increased and the load - deflection curve is plotted by INSTROM device.

5- Photo capturing the billet, through the acrylic surface and it moves till finishing the process.

6 - The process is repeated by changing the type of spring.

\section{RESULTS AND DISCUSSION}

This article includes details of result and discussions, which have been got from the theoretical analysis by using ANSYS program and the results from experimental part using the extrusion apparatus that was designed and manufactured for this research which contains the spring that was used to find the best die angle and the best die design and a comparison is made between them. 
Distribution of Stresses in Extrusion Process: The study of stress distributions at different stiffness of springs that are linked to the die follows the movement of billet inside the die. The speed of the particles in the internal area of the specimen would be greater than the adjacent areas, till reaching the surface of die, because the substance is pushed in the field due to constant volume and obstruction the die's wall to the movement of the particles near the surface this is same as the speed of particle in the middle due to friction, and after a distance towards $x$-axis, In the outlet of the die, it is noticed that the metal's speed at the axisymmetric axis is seem to be constant but the speed of particle that is near the die surface, begins to increase, therefore, the metal speed would be at the end of area from the die, equal in all directions due to the constant of the vertical and horizontal components .

The following figures represent the stress distributions (Von-Mises stress) in the billet according to ANSYS program at inlet, middle and outlet of the die. Twelve cases studied, according to the coefficient of friction $\mu(0.005,0.008,0.015)$ each one with four tests according to the stiffness of spring $(0,100,1000,10000) \mathrm{N} / \mathrm{mm}$. and the reduction of area were variable in two cases with lubricate $(16.6,22.2,27.7)$ and without lubricate (22.2, $24.4,26.6)$. Fig. (11) shows the equivalent stress distribution using friction coefficient of 0.005 , (i.e. High lubricant case), with several positions of the billet inside the die and different spring stiffness'. Fig. (11a) shows the stress distribution using zero spring stiffness. Figs. (11.b, 11.c, and 11.d) show the stress distribution using spring stiffness of $(100 \mathrm{~N} / \mathrm{mm}, 1000 \mathrm{~N} / \mathrm{mm}$, and 10000 $\mathrm{N} / \mathrm{mm}$, respectively). Its is noticeable that the increases in the spring stiffness would increase the uniformity of the metal extrusion, where the particle speed do not increased due to extrusion when the stiffness increased. As well as the increases of spring stiffness' would lead to unaffected the particle at the other end of the metal. Figs. (12.a through 12.d) show the equivalent stress distribution (as in Fig (11) above), but the coefficient of friction is changed to be equal to 0.008 (i.e. low lubricant case) with several positions of the billet inside the die and different spring stiffness'. Fig. (13) shows the equivalent stress distribution when the coefficient of friction is equal to 0.015 (i.e. without lubricant case) with several position of the billet inside the die, when the stiffness of spring is equal to zero Fig.(13.a), equal to $100 \mathrm{~N} / \mathrm{mm}$ Fig. (13.b), equal to $1000 \mathrm{~N} / \mathrm{mm}$ Fig.(13.c), and equal to $10000 \mathrm{~N} / \mathrm{mm}$ Fig (13.d). 

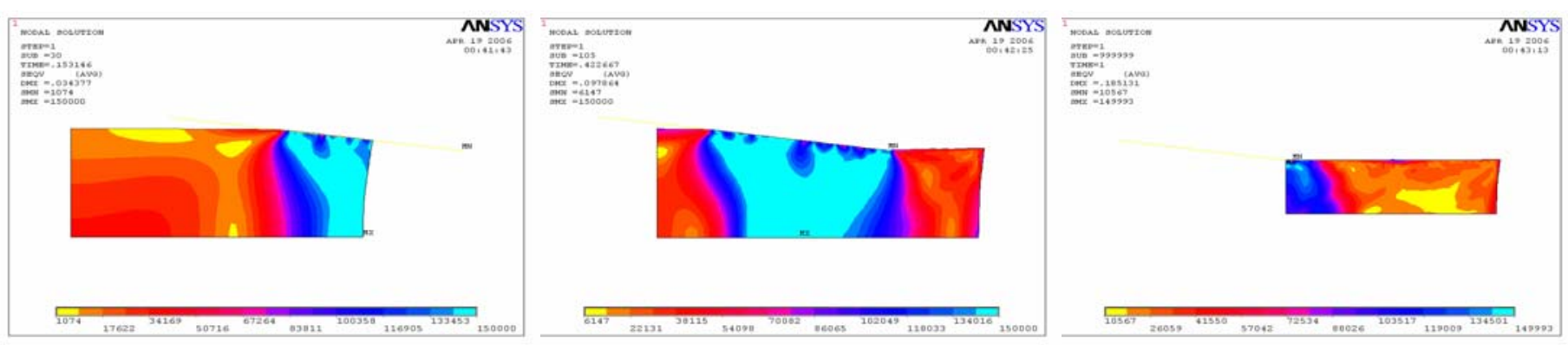

-a-
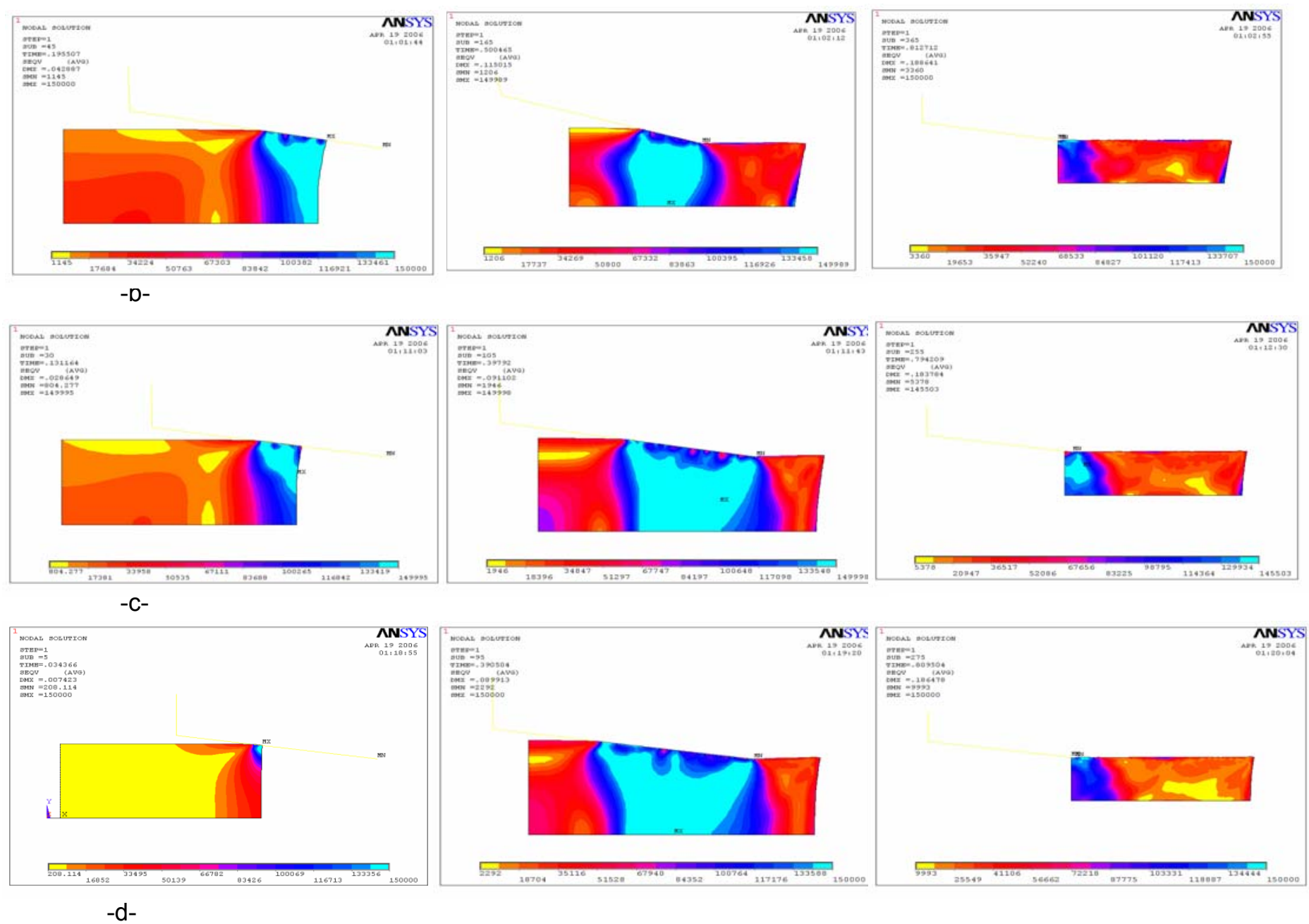

Fig 11: Stress distribution when coef. of friction $=0.005$

a- when $\mathrm{K}=0$, b- when $\mathrm{K}=100 \mathrm{~N} / \mathrm{mm}$, c- when $\mathrm{K}=1000 \mathrm{~N} / \mathrm{mm}$, d- when $\mathrm{K}=10000 \mathrm{~N} / \mathrm{mm}$ 

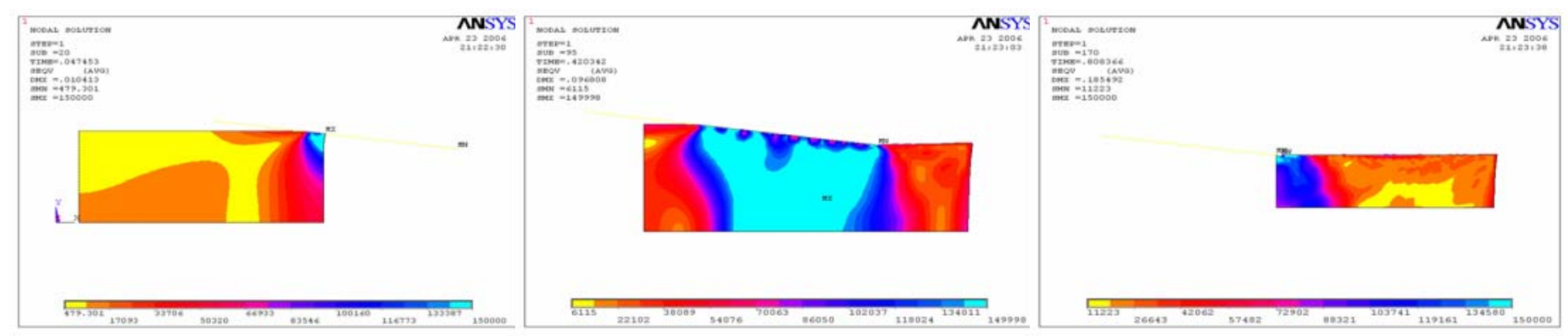

-a-
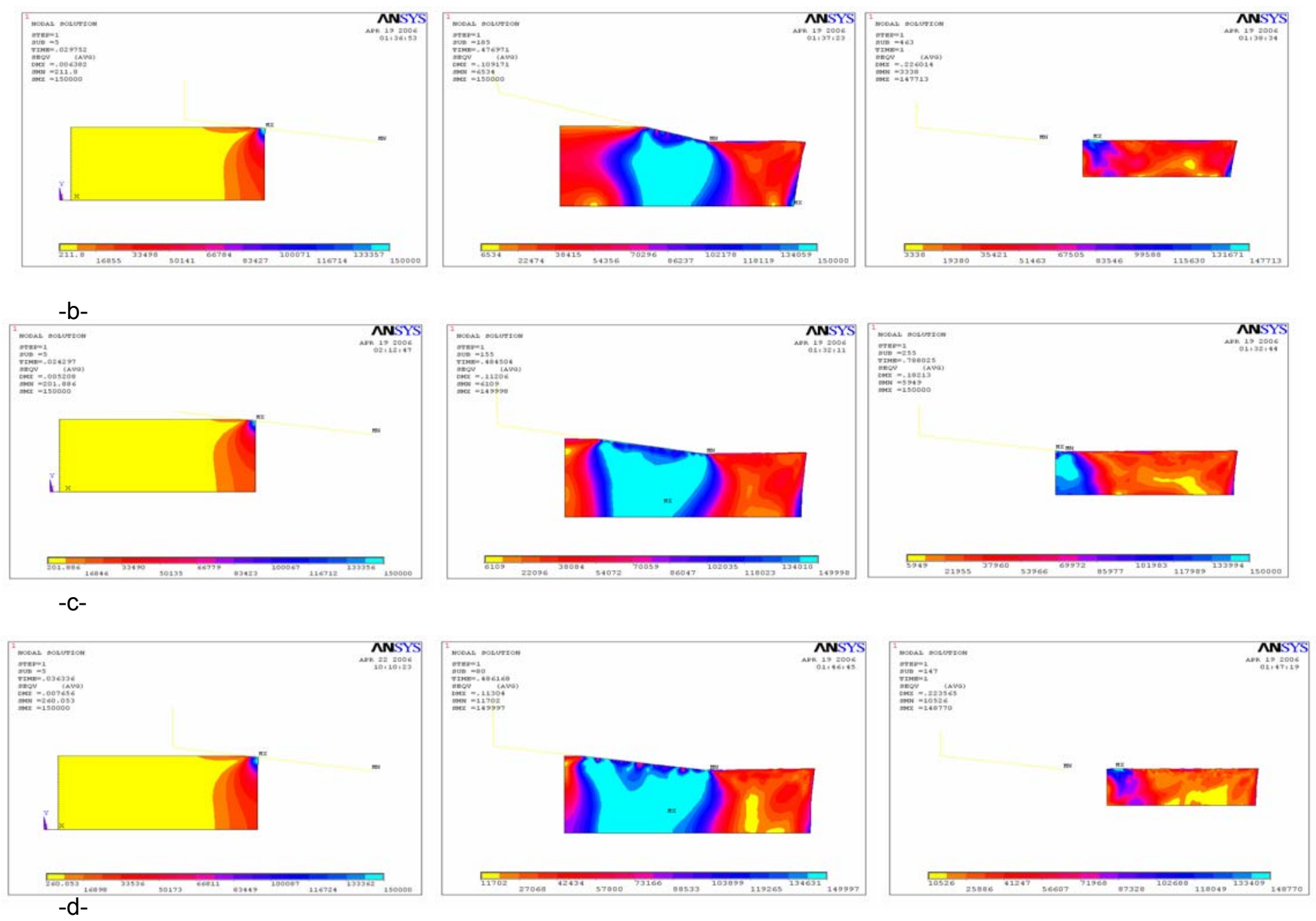

Figure 12: Stress distribution when coef. of friction $=0.008$

a- when $\mathrm{K}=0 \quad$, b- when $\mathrm{K}=100 \mathrm{~N} / \mathrm{mm}$, c- when $\mathrm{K}=1000 \mathrm{~N} / \mathrm{mm}$, d- when $\mathrm{K}=10000 \mathrm{~N} / \mathrm{mm}$ 


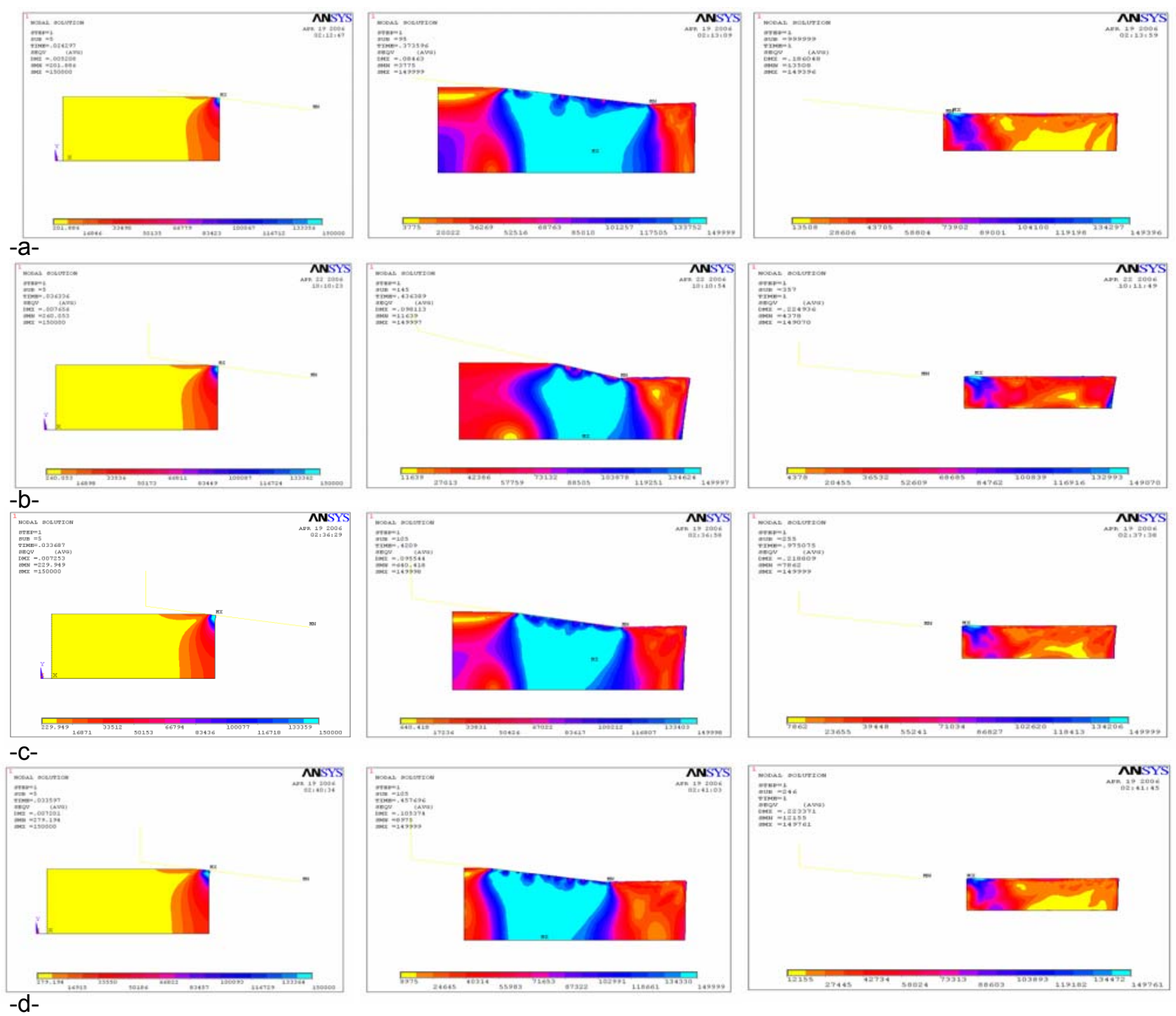

Figure 13: Stress distribution when coef. of friction $=0.015$ a- when $\mathrm{K}=0$, b- when $\mathrm{K}=100 \mathrm{~N} / \mathrm{mm}$, c- when $\mathrm{K}=1000 \mathrm{~N} / \mathrm{mm}$, d- when $\mathrm{K}=10000 \mathrm{~N} / \mathrm{mm}$

\section{Maximum Extrusion Stress}

Table (4) contains all the maximum extrusion stresses in case of $\mu=0.005$ (with high lubricant) with linked to spring $(\mathrm{K}=100 \mathrm{~N} / \mathrm{mm}), \quad(K=1000$ $\mathrm{N} / \mathrm{mm}),(\mathrm{K}=10000 \mathrm{~N} / \mathrm{mm})$

Table (5) contains all the maximum extrusion stresses in case of $\mu=0.008$ (with low lubricant) with linked to spring ( $K=100 \mathrm{~N} / \mathrm{mm}), \quad(K=1000$ $\mathrm{N} / \mathrm{mm}),(\mathrm{K}=10000 \mathrm{~N} / \mathrm{mm})$.

Table (6) contained all the maximum extrusion stresses in case of $\mu=0.015$ (without lubricant) with linked to spring $(K=100 \mathrm{~N} / \mathrm{mm}), \quad(K=1000 \mathrm{~N} / \mathrm{mm})$, $(\mathrm{K}=10000 \mathrm{~N} / \mathrm{mm})$. 
Am. J. Sci. Ind. Res., 2010, 1(2): 164-179

Table 4: Equivalent stress in Pa when $\mu=0.005$

\begin{tabular}{|l|l|l|l|}
\hline Position & INLET die & MIDDLE die \\
$(\mathrm{P}) \mathrm{a}$ & & $\begin{array}{c}\text { OUTET die } \\
\text { (Pa) }\end{array}$ \\
\cline { 1 - 1 } Stiff. of spring (N/mm) & 150000 & 150000 & 149993 \\
\hline $\mathrm{K}=0$ & 150000 & 149989 & 150000 \\
\hline $\mathrm{K}=100$ & 149995 & 149998 & 145503 \\
\hline $\mathrm{K}=1000$ & 150000 & 150000 & 150000 \\
\hline
\end{tabular}

Table 5: Equivalent stress in Pa when $\mu=0.008$

\begin{tabular}{|l|l|l|l|}
\hline Position & \multirow{2}{*}{ INLET $(\mathrm{Pa})$} & MIDDLE $(\mathrm{Pa})$ & \multirow{2}{*}{ OUTLET $(\mathrm{Pa})$} \\
\hline $\mathrm{K}=0$ & 150000 & 149998 & 150000 \\
\hline $\mathrm{K}=100$ & 150000 & 150000 & 147713 \\
\hline $\mathrm{K}=1000$ & 150000 & 149998 & 150000 \\
\hline
\end{tabular}

Table 6: Equivalent stress in Pa when $\mu=0.015$

\begin{tabular}{|l|l|l|l|}
\hline \multirow{2}{*}{ Position } & \multirow{2}{*}{ INLET $(\mathrm{Pa})$} & MIDDLE $(\mathrm{Pa})$ & \multirow{2}{*}{ OUTLET $(\mathrm{Pa})$} \\
\cline { 1 - 4 } Stiff. of spring & 150000 & 149999 & 149396 \\
\hline $\mathrm{K}=0$ & 150000 & 149997 & 149070 \\
\hline $\mathrm{K}=100$ & 150000 & 149998 & 149999 \\
\hline $\mathrm{K}=1000$ & 150000 & 149999 & 149761 \\
\hline
\end{tabular}

The previous data can be drawn as plots to see the variation in equivalent stresses in the billet with different spring's stiff nesses. It can be deduced that the different in the results is not far away because the ultimate stresses equal to the yield stresses.

Fig.(14) shows the variation in max. stress in the billet at different spring's stiff nesses

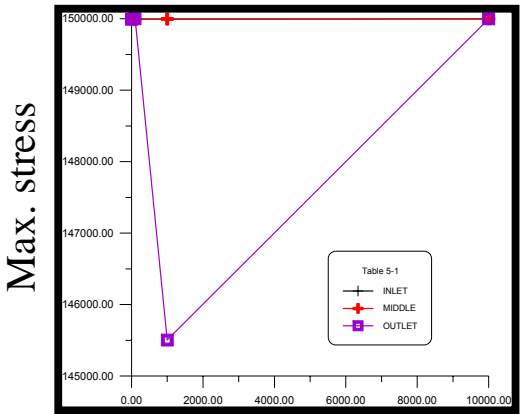

-a-

Stiffness of Spring



$-b-$

Stiffness of Spring

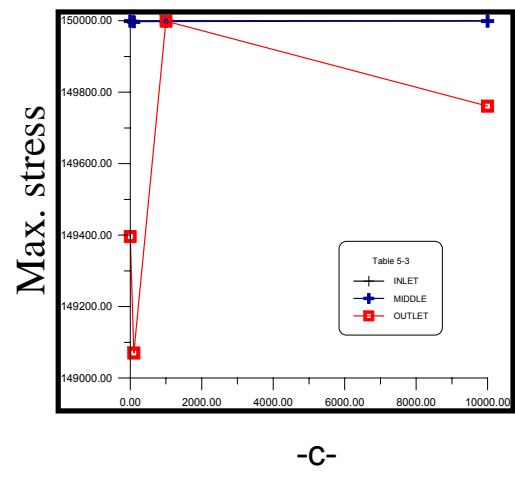

Stiffness of Spring

Fig 14: The variation of max. Stress with different stiffness of spring when
(a) $\mu=0.005$
(b) $\mu=0.008$
(c) $\mu=0.015$

From Fig.(14) when the coef. of friction is 0.005 it shows that the stress decrease at $K=1000 \mathrm{~N} / \mathrm{mm}$ and increases at $K=10000 \mathrm{~N} / \mathrm{mm}$, and when the coef. of friction increased $(=0.008)$, It can be seen that the stress increases when the stiffness increased but decreases at $\mathrm{K}=10000 \mathrm{~N} / \mathrm{mm}$, in the above two cases the lubricant is used. But when the coefficient of friction increases to 0.015 it is noticed that the stress increases with the increasing the stiffness of spring, but with high stiffness (10000 $\mathrm{N} / \mathrm{mm}$ ), it increases with a little amount when $(\mu=0.008)$ because this case is without lubricant.

Force - Displacement Relation: Figures(15), (16) \& (17) show the force - displacement relation, it is noticed from these figures, that when using the different stiffness constants of spring, all participate in increasing the stiffness of spring corresponding to decrease in the load and vice versa. 
Am. J. Sci. Ind. Res., 2010, 1(2): 164-179

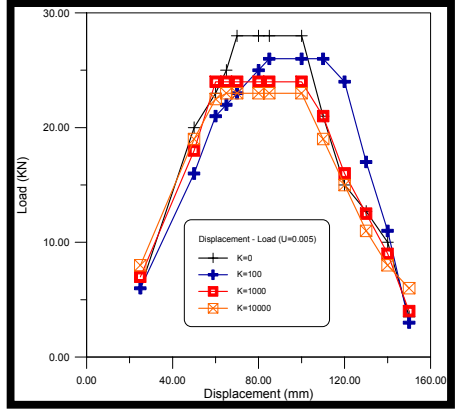

Fig 15: Disp. vs load $\mu=0.005$

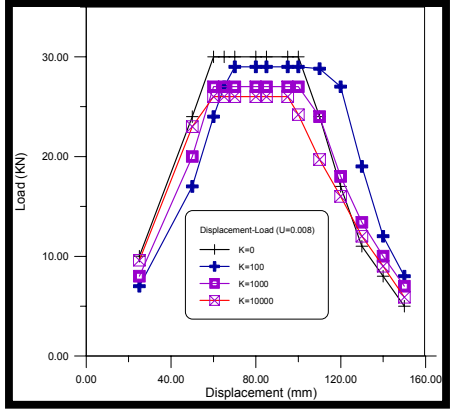

Fig 16: Disp. vs load $\mu=0.008$

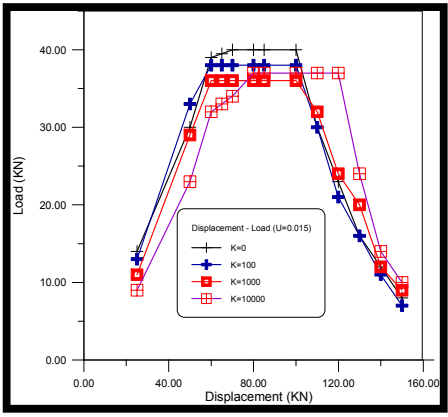

Fig 17: Disp. vs load $\mu=0.015$
Semi- Angle of Extrusion Die: Figs. (18), (19) and (20) show the relations between the die angle $(\alpha)$ and the punch displacement with different value of coef. of friction and stiffness constant of spring. From Fig. (18), it can be concluded that when the punch displacement increases the die angle increases till the displacement is equal to $(45 \mathrm{~mm})$ then it is still constant until displacement $=105 \mathrm{~mm}$. After that the displacement would be decreased with the punch displacement and the max. angle is equal to $16^{\circ}$ when the punch displacement is between (78-118)mm with stiffness equal 100 $\mathrm{N} / \mathrm{mm}$ and it is the worse case, thus when the stiffness increases the angle will be decreased as shown, and the best is when $k=10000 \mathrm{~N} / \mathrm{mm}$, with angle equal $8.7^{\circ}$. From Fig.(19), it can be concluded that when the punch displacement increases the die angle increase till the displacement equals $(45 \mathrm{~mm})$ then it is still constant until displacement $=105 \mathrm{~mm}$ after that the displacement would be decreased with the punch displacement and the max. angle is equal to $28^{\circ}$ when the punch displacement is between (78118) $\mathrm{mm}$ with stiffness equal $100 \mathrm{~N} / \mathrm{mm}$ and it is the worst case, thus when the stiffness increases the angle will be decreased as shown, and the best is when $\mathrm{K}=10000 \mathrm{~N} / \mathrm{mm}$, with angle equal $8.7^{\circ}$. From Fig. (20), it can be concluded that when the punch displacement increases the die angle increases till the displacement is equal to $(45 \mathrm{~mm})$ with $(\mathrm{K}=1000$ $\mathrm{N} / \mathrm{mm}$ \& $10000 \mathrm{~N} / \mathrm{mm}$ ) and equal $(80 \mathrm{~mm})$ with $(\mathrm{K}=100 \mathrm{~N} / \mathrm{mm})$ then it is still constant until displacement $=105 \mathrm{~mm}$ after that the displacement would be decreased with the punch displacement and the max. angle is equal to $15^{\circ}$ when the punch displacement is between (78-118) $\mathrm{mm}$ with stiffness equal 100 and it is the worst case. Thus when the stiffness increases the angle will be decreased as shown, and the best is when $\mathrm{K}=10000 \mathrm{~N} / \mathrm{mm}$, with angle equal $8.7^{\circ}$.

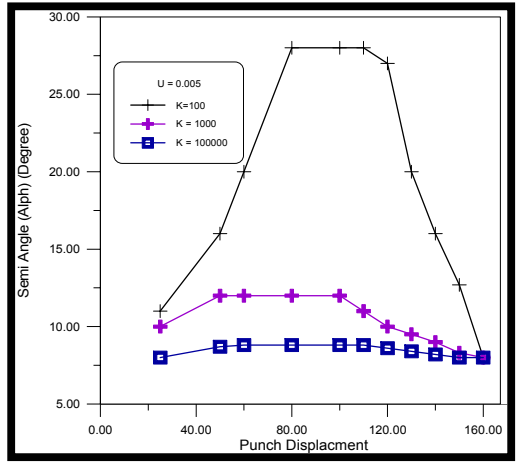

Fig 18: $\mu=0.005$

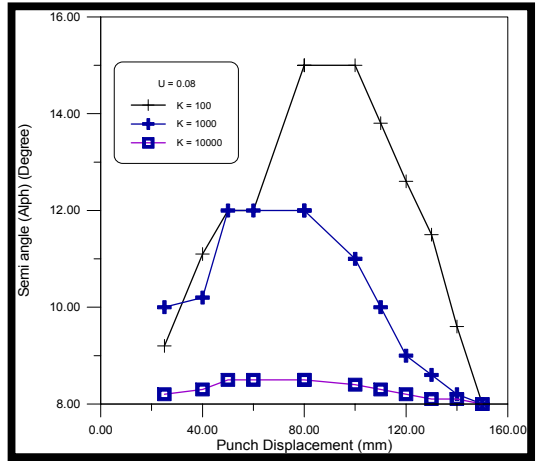

Fig $19: \mu=0.008$

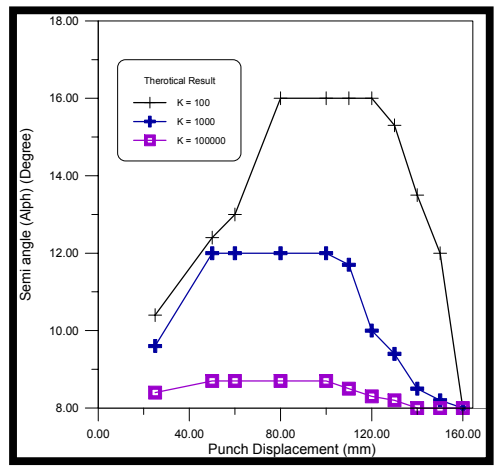

Fig 20: $\mu=0.015$ 
Experimental Results: Fig.(21) shows the extrusion process using our apparatus that is built for this purpose, as shown the spring linked to the die is compressed with the flow of the billet and change in the die angle, as a result of forces changing and stresses. The data of spring using is:The stiffness of spring $K=10000 \mathrm{~N} / \mathrm{mm}, D_{0}=18 \mathrm{~mm}$, $\mathrm{d}_{\text {coil }}=3 \mathrm{~mm}$ and the height of spring at the initiated of the process is $\left(h_{0}=30 \mathrm{~mm}\right)$ and at the final process is $\left(h_{f}=17 m m\right)$. This case is treated without lubricant (i.e. $\mu=0.015$ ). Fig.(22) shows the using of lubricant $(\mu=0.005$ and $\mu=0.008)$ at $(K=10000 \mathrm{~N} / \mathrm{mm})$. Fig. (23) shows the extrusion process with the data of spring using is:-

The stiffness of spring $K=1000 \mathrm{~N} / \mathrm{mm}, D_{0}=18.3 \mathrm{~mm}$, $\mathrm{d}_{\text {coil }}=2.3 \mathrm{~mm}$ and the height of spring at the initiated of the process is $\left(h_{0}=30 \mathrm{~mm}\right)$ and at the final process is $\left(h_{f}=18 \mathrm{~mm}\right)$. This case is treated without lubricant (i.e. $\mu=0.015$ ). Fig.(24) shows the using of lubricant $(\mu=0.005$ and $\mu=0.008)$ at $(K=1000$ $\mathrm{N} / \mathrm{mm}$ ). Fig.(25) shows the extrusion process with the data of spring used is:-

The stiffness of spring $K=100 \mathrm{~N} / \mathrm{mm}, D_{0}=17.5 \mathrm{~mm}$, $\mathrm{d}_{\text {coil }}=2 \mathrm{~mm}$ and the height of spring at the initiated of the process is $\left(h_{0}=30 \mathrm{~mm}\right)$ and at the final process is $\left(h_{f}=21 \mathrm{~mm}\right)$. This case is treated without lubricant (i.e. $\mu=0.015$ ). Fig.(26) shows the using of lubricant $(\mu=0.005$ and $\mu=0.008)$ at $(K=100 \mathrm{~N} / \mathrm{mm})$.
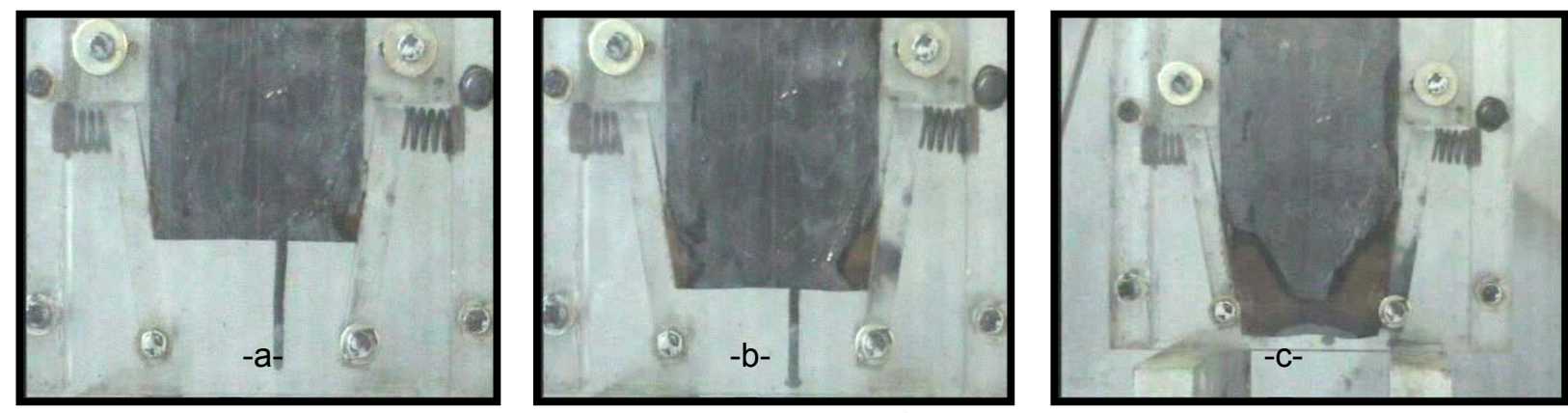

Figure 21: The extrusion process using the spring $(K=10000 \mathrm{~N} / \mathrm{mm}$ ) linked to the die with $\mu=0.015$ ( without lubricant) (a) at inlet (b) in the middle of the die (c) at the outlet of the die
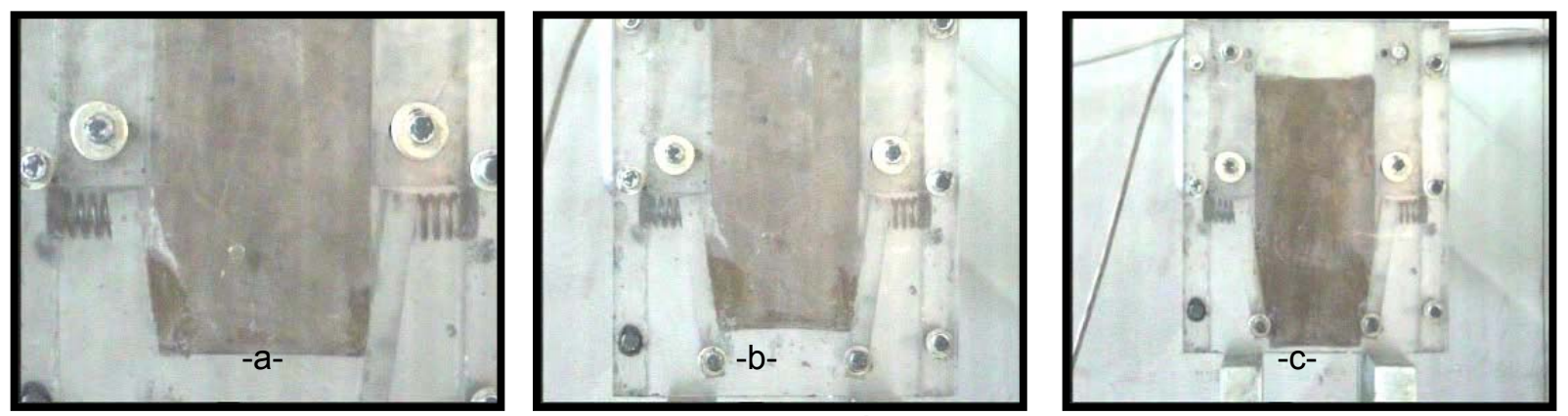

Figure 22: The extrusion process using the spring $(\mathrm{K}=10000 \mathrm{~N} / \mathrm{mm})$ linked to the die with $\mu=0.005,0.008$ (without lubricant) (a) at inlet (b) in the middle of the die (c) at the outlet of the die
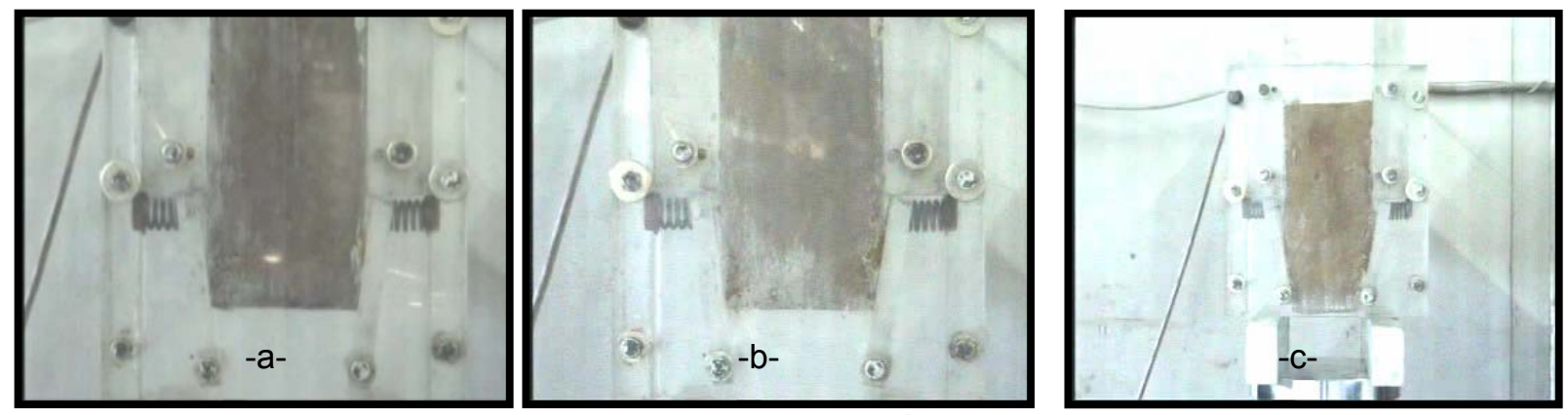

Figure 23: The extrusion process using the spring $(\mathrm{K}=1000 \mathrm{~N} / \mathrm{mm})$ linked to the die with $\mu=0.015$ ( without lubricant) (a) at inlet (b) in the middle of the die (c) at the outlet of the die 
Am. J. Sci. Ind. Res., 2010, 1(2): 164-179
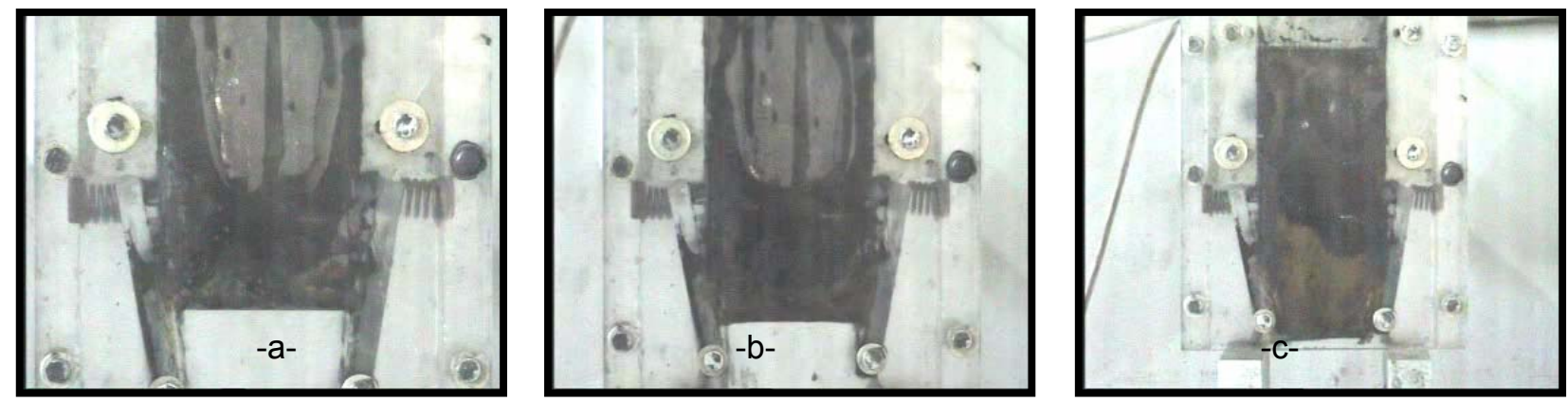

Figure 24: The extrusion process using the spring $(\mathrm{K}=1000 \mathrm{~N} / \mathrm{mm})$ linked to the die with $\mu=0.005,0.008$ ( with lubricant) (a) at inlet (b) in the middle of the die (c) at the outlet of the die
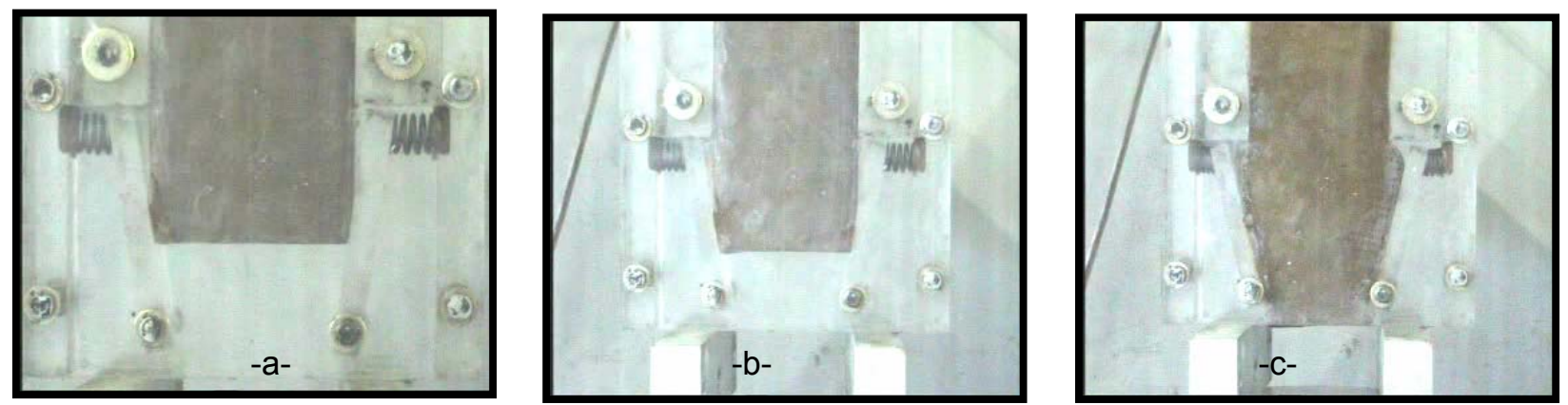

Figure 25: The extrusion process using the spring $(K=100 \mathrm{~N} / \mathrm{mm}$ ) linked to the die with $\mu=0.015$ ( without lubricant) (a) at inlet (b) in the middle of the die (c) at the outlet of the die
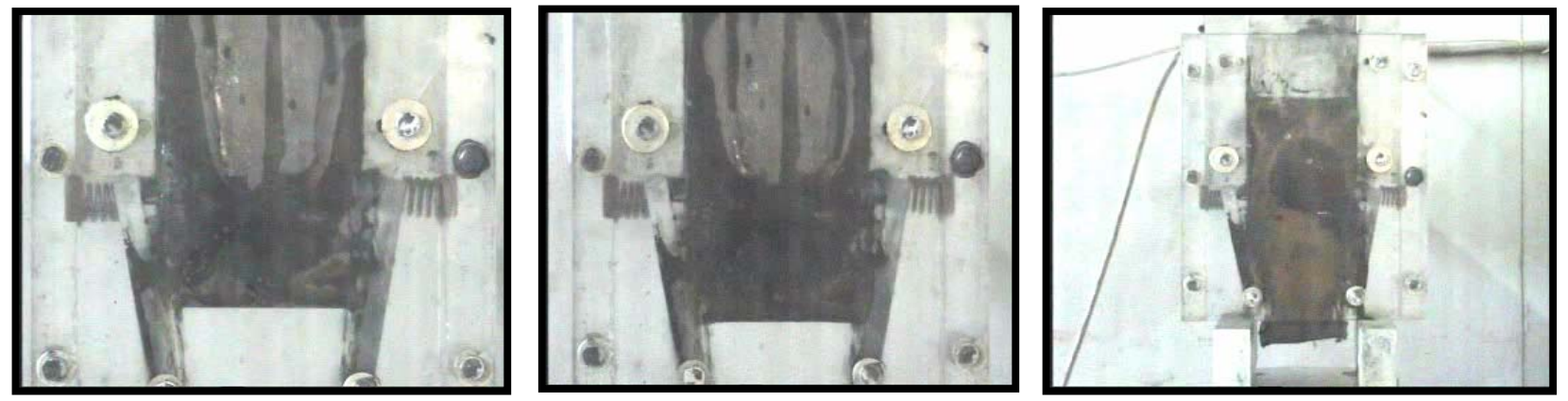

Figure 26: The extrusion process using the spring $(\mathrm{K}=100 \mathrm{~N} / \mathrm{mm})$ linked to the die with $\mu=0.005,0.008$ (with lubricant) (a) at inlet (b) in the middle of the die (c) at the outlet of the die

\section{CONCLUSIONS}

From the theoretical and experimental works, some one can concluded that the force needed to make the extrusion process is increased with decreasing the stiffness of spring i.e. when the stiffness of spring increases, it get the less force. The relation between the equivalent stresses and the stiffness of spring increases with increase the stiffness of spring till it becomes constant and then decreases.
The best semi- angle of the die that is concluded in this study is $\left(16^{\circ}\right)$ without using lubricant $(\mu=0.015)$ and $\left(8.7^{\circ}\right)$ when lubricant $(\mu=0.005)$ is used and the worst semi-angle is $\left(16^{\circ}\right)$ without lubricant and $\left(28^{\circ}\right)$ with lubricant. The relation between the force and displacement in the theoretical part represents the perfect case for the extrusion process using the spring to link the die; this relation is direct relation, because the forming process occurs, till the force reaches to maximum value. After the forming 
process is finished and due to constant area at the outlet of the die the force is decreased.

The relation between the force and displacement in the experimental part represents the actual case of the extrusion process with die linked to spring, in which the force increases with the extrusion displacement inside the die, till the forming process is finished, then the force has still the same value with displaced sample until it exits from the outlet of the die. That is because to the paraffin wax is a perfect plastic material.

\section{REFERENCES}

[1] Altan.T.O.S.I and Gegel H.L. "Metal Forming American Society for Metals", Metals Park, Ohio, 1983.

[2] Balaji T. ,Sundararajan P.A. and Lai E.K. "Viscoplastic Deformation Analysis and Extrusion Die Design by Finite Element Method" J. Appl. Mech. Trans. ASME, 644-650,1991.

[3] Banabic D. "Formability of Metallic Materials", 2000.

[4] Bhavin, V.M., Gunasekera J.S., Kapadia A. and Yu Z., "CAE of Extrusion Dies for Metal and Polymers Flows"

(http://books.google.com/books?hl=en\&lr=\&id=DMY XKb9C9boC\&oi=fnd\&pg=PR19\&dq=CAE+of+extrusi on+dies+for+metal+and+polymers+flows\&ots=nxNht
-RoOh\&sig=-tA6I5Fmubat NSUbPV T ik S3bM0M ), 2005.

[5] Frisch J. \& Pietri E.M. "Experiments and the Upper Bound Solution in Axisymetric Extrusion", Proceeding of the 18 int. machine tool designers. Conference, the Imperial College, London 1977.

[6] Johnson W. \& Mellor P.B. "Engineering Plasticity "1972.

[7] Kobayshi S.S.Oh. and Altan T. "Metal Forming and the Finite Element Method " Oxford University Press, 1989 .

[8] Nayak A.C. and Zienkiewicz O.C. "Elasto-Plastic Stress Analysis. A Generalization for Various Constitutive, Relations Including Strain Softening" Int. J. Num. Meth .Eng., 5,113-135, 1972.

[9] Onuh S. O. "Effect of Die Geometry and Extrusion Speed on the Cold Extrusion of Aluminum and Lead Alloys" , Journal of Material Processing Technology, Vol.132, pp.274-285, 2003.

[10] Osaka, K, Nakano,J. and Mori, K. " Finite Element Method for Rigid- Plastic Analysis of Metal Forming Formulation for Finite Deformation". Int. J. Mech. Sci., Vol. 24, pp.459-468, (1982)

[11] Shabaik A .H and Thumson E.G. "Theoretical Method for the Analysis of Metal Working Problems" , J. Eng. Ind. Trans. ASME, 343-352, 1986.

[12] User's Manual of FEA/ANSYS/Version 10/2006. 